\title{
Five-to-five clear aligner therapy: predictable orthodontic movement for general dentist to achieve minimally invasive dentistry
}

\author{
Tommaso Weinstein ${ }^{1 *}$ (D) Giuseppe Marano ${ }^{2}$ and Raman Aulakh ${ }^{3}$
}

\begin{abstract}
Background: Esthetic dentistry has become a very important aspect of every dental treatment from the patient perspective, whether it is orthodontics or implant therapy. The aim of this article is to describe the advantages of a newly developed branch of five-to-five clear aligner therapy (CAT) (Invisalign Go, Align Technology, San Jose, Calif) in interdisciplinary treatments especially in terms of minimally invasive interventions.

Case presentation: Two case reports are presented together with a comprehensive analysis using the SAFE (Safety, Assessment, Function, Ethics) assessment. This paper aims to introduce a new systematic in CAT. Invisalign Go (Align Technology, Santa Clara, California, USA) allows orthodontic treatment from second premolar and second premolar in both arches. It is specially designed for general practitioners devoted to restorative dentistry for a better planning of a multidisciplinary and mini-invasive treatment plan.
\end{abstract}

Discussion and conclusion: The clinical results demonstrate how CAT is extremely useful in multidisciplinary treatment plan in order to straighten teeth especially in a pre-restorative phase to allow minimally invasive and adhesive restorations.

Keywords: Clear aligner therapy, Minimal invasive dentistry, Restorative dentistry, Digital impression, Interdisciplinary treatment planning

\section{Backgound}

Esthetic dentistry has become a very important aspect of every dental treatment from the patient perspective, whether it is orthodontics or implant therapy [1]. In a recent survey study by Azarpazhooh et al. [2] questioning patient values related to treatment preferences for a tooth with apical periodontitis, esthetic outcome was the third among the most determining treatment preferences after communication/trust and retention.

Esthetics is not something separate from routine dentistry, indeed it "incorporates biological considerations to

\footnotetext{
${ }^{*}$ Correspondence: tommasoweinstein@me.com

${ }^{1}$ Humanitas Dental Center, Humanitas Research Hospital, Rozzano, MI, Italy

Full list of author information is available at the end of the article
}

achieve the ideal function and emulate the pristine natural dentition, with a view to long-term performance and survival" [3].

Together with this, the relationship between patient and dentist has shifted from the paternalistic system to a new kind of relationship, a therapeutic alliance where the patient is able to make an informed decision based on scientifically based opinion made by his/her doctor [4].

In this perspective, new technologies allow dentist to show and inform the patient with a pre-visualization of the esthetic treatment. In restorative dentistry instruments such Digital Smile Design [5, 6] has changed the workflow throughout presenting treatment plan to patients. 
Furthermore, minimally invasive dentistry, defined as "a systematic respect for the original tissue" $[7,8]$ has become a standard approach to solve dental pathologies.

This kind of approach is beneficial for esthetic treatment because it is possible to correct esthetical deficiencies with minimal interventions.

One of the most challenging situations is the correction of malpositioned teeth in adults from a restorative point of view.

To overcome this issue a valuable alternative is clear aligner therapy (CAT) which allows orthodontic movements by using removable thermoplastic appliances with modern CAD-CAM stereolithography and tooth movements simulation software [9]. It was introduced by Align Technology (Santa Clara, California, USA) in 1999 combining the concepts developed by Kesling [10], Ponitz [11] and McNamara [12].

CAT is better perceived by adult population than the conventional orthodontic therapies with braces because of esthetics.

The aim of this paper is to present two different cases where a specific CAT, treating only from second premolar to second premolar in both arches (Invisalign GO Align Technology, San Jose, Calif), was used in multidisciplinary treatment plans as a pre-restorative treatment in order to perform minimally invasive interventions.

\section{Cases presentation}

All the cases were carefully evaluated with the SAFE assessment. SAFE assessment stands for Stability Assessment Function and Ethics. This assessment was created by one of the authors (Raman Aulakh) and used in other case reports $[13,14]$ in order to encompass orthodontics and restorative dentistry. It had to synchronize with Facially Generated Treatment Planning (FGTP) $[15,16]$. The analysis for each case is reported in a dedicated table.

\section{Case 1}

A 35 years old man complained about his broken upper left central incisor, upper right lateral crossbite, diastema between 2.3 and 2.4 and crowding in the lower arch. There were no temporo-mandibular joint (TMJ) nor muscles signs of pathologies. The treatment plan aimed to correct, by means of clear aligner therapy, the misalignment, and fix the tooth 2.1 with a direct restoration. The clear aligner therapy was performed with Invisalign Go (Align Technology, San Jose, Calif) a system specifically designed for general practitioner involved in restorative dentistry with movements from second premolar to second premolar in both arches. The feasibility of the treatment is assessed through a dedicate app (Invisalign Photo Uploader) where a precise sequence of photos is uploaded (Figs. 1a-c and 2a-e).

The SAFE assessment of the case is reported in Table 1.

A digital impression (Fig. 3) was taken by means of an iTero scanner (Align Technology, San Jose, Calif) and sent for the Clin Check (Align Technology, San Jose, Calif; Fig. 4a, b), the software used for 3D alignment simulation. After the clinician had approved the Clin Check, the aligners were produced. Attachments were positioned and interproximal reduction was performed where needed following instructions of the manufacturer and a first set of aligners was positioned (Fig. 5). The therapy consisted of 12 aligners, patient was instructed to wear them at least $20 \mathrm{~h}$ a day, changing weekly, clinical control every 4 weeks. At the end of the treatment a new digital impression for a light refinement of the lower crowding was requested, for a total of 9 additive aligner with the same protocol. Cross bite, diastemas and crowding were resolved and direct restoration on tooth 21 was performed (Fig. 6a, b). Patient was happy with the final result (Figs. 7a-e and 8a, b) and a final digital impression (Fig. 9) was taken in order to have removable retainer (Vivera, Align Technology, San Jose, Calif) to be worn by night.

\section{Case 2}

A 29 years old woman asked for consultation because she was near to her marriage, but unsatisfied about her smile. Clinical evaluation found a cross-bite of lower right canine and tooth discrepancy on upper right lateral incisor which was smaller than the contralateral (Figs. 10a-e, 11, 12). No signs of temporo-mandibular joint (TMJ) or muscles disease were detected. The SAFE assessment of the case is reported in Table 2.

The treatment plan involved CAT to correct the cross bite and create a correct mesio-distal distance from 1.1 to 1.3 for a re-shaping of tooth 1.2 with a direct restoration.

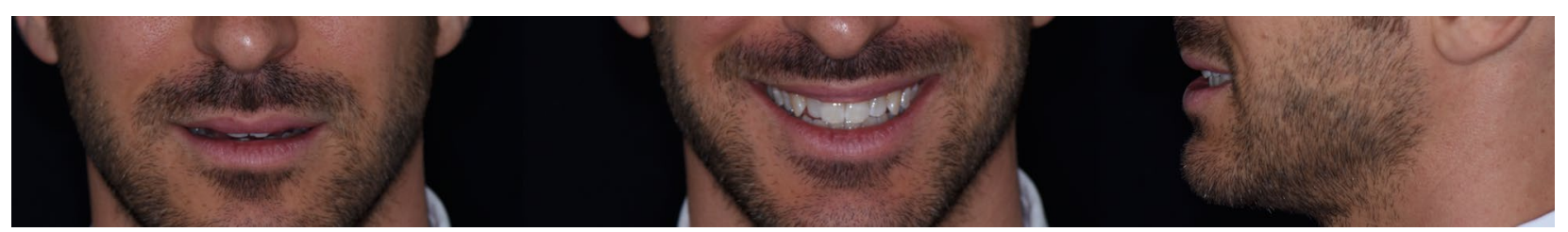

Fig. 1 Case 1, initial situation. Extraoral views 


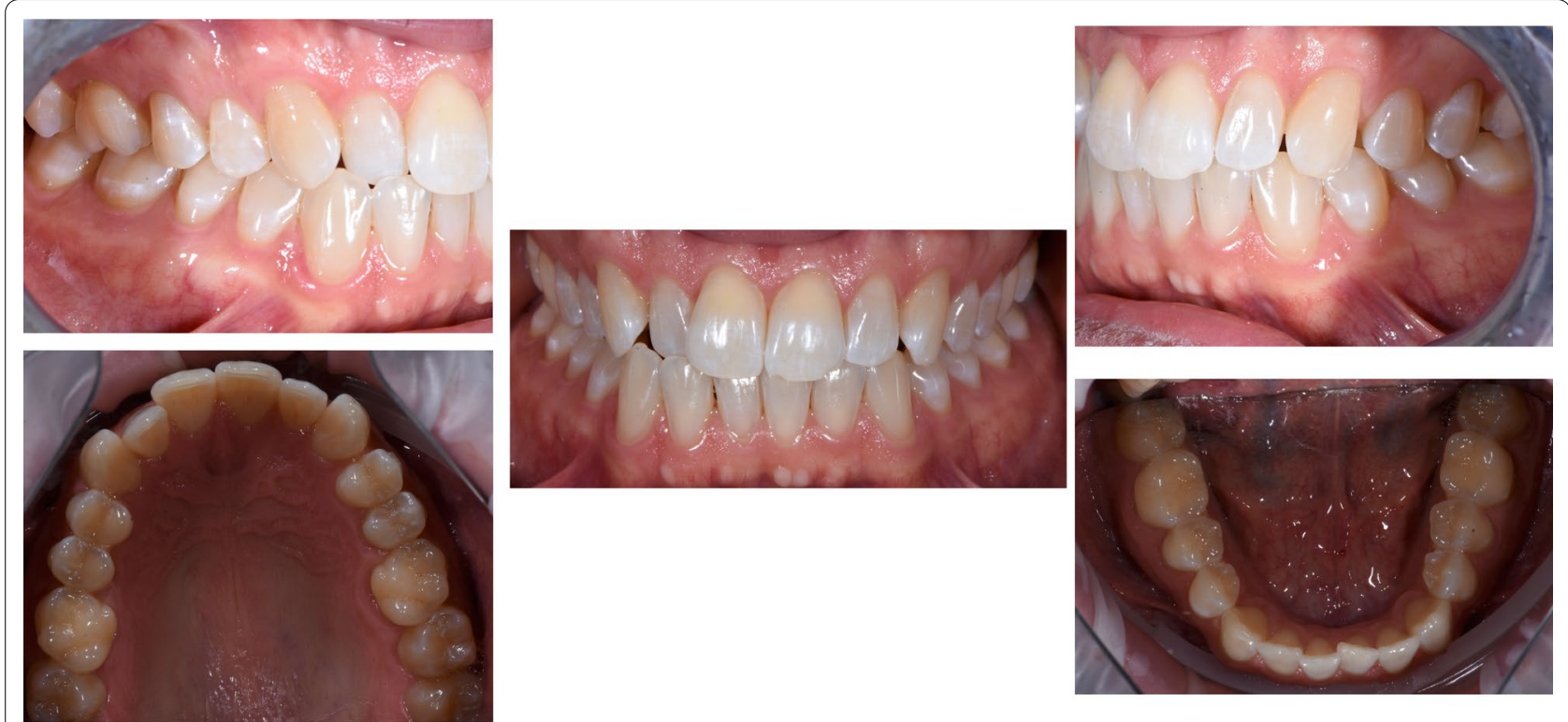

Fig. 2 Case 1, initial situation, intraoral views

Patients disliked any solution with indirect restoration such as a veneer on tooth 1.2 which was proposed as an alternative treatment plan. The clinical procedure followed the pathways of Invisalign Go (Align Technology, San Jose, Calif) described in the previous case and detailed in Fig. 13.

The Clin Check was carefully planned in order to correct the cross bite but also to create the correct space for tooth 1.2 which was calculated through Bolton analysis [17] with 14 phases. (Figs. 14, 15). Refinement was needed in order to improve the alignment and opening the adequate space for tooth 1.2 and consisted in 9 additional aligners (Fig. 16).

Once the CAT was ended (Fig. 17a-e), a direct restoration on tooth 1.2 was made. Life-long retention protocol with Vivera Retainer (Align Technology, San Jose, Calif) was recommended (Fig. 18a-e).

\section{Discussion and conclusion}

The patient evaluation in any complex rehabilitation should follow a pattern, a systematic approach which helps clinicians to elaborate the treatment plan [18-21]. Spear and Kokich elaborated the so called Facially Generated Treatment Planning (FGTP): the key reference point is an upper central incisor, and his position should be planned first in relation to face and lips $[15,16]$.

The FGTP uses the face to determine where the teeth, gingiva, and papillae should be positioned and then creating the rest of the treatment plan around the facially driven tooth position. The same that happens with a complete denture.
After determining the position of the central incisor and related esthetics there are three more steps to follow: function, structure and biology.

This sequence should always be followed to correctly plan the treatment; the operative sequence could otherwise be different. Esthetics has to be planned first in order to have a better final outcome and digital technologies could be very helpful [6].

The FGTP is a guide to inter-disciplinary planning, it allows for realistic treatment goals to be set for adults with a vision shared by the whole team. It is also a potential tool to communicate with the patient. It is a comprehensive analysis of the case which can be usefully used to understand the case and elaborate a correct treatment plan especially built for a prerestorative phase with aligners. The SAFE assessment transposes all these concepts with focus into orthorestorative cases with CAT. It is a comprehensive assessment which allows general practitioners as well as specialist orthodontists to deeply analyze and plan any cases. CAT is a well-established technique to straighten teeth. It is an alternative to fixed braces able to treat quite every kind of malocclusion [22]. A systematic review stated that CAT is able to align and level the arches in adults [23]. CAT is better experienced especially in adults because of less pain and better quality of life [24]. It could be optimal also for per periodontal tissues: during treatment the opportunity to remove clear aligners makes easy the oral hygiene and determines better periodontal 
Table 1 Safe assessment case 1

\begin{tabular}{|c|c|c|c|c|c|c|c|}
\hline \multirow{2}{*}{\multicolumn{2}{|c|}{$\begin{array}{l}\text { Esthetics } \\
\text { Face: frontal view }\end{array}$}} & \multicolumn{2}{|l|}{ Occlusion (static and functional) } & \multicolumn{2}{|c|}{ Structure } & \multicolumn{2}{|l|}{ Biology } \\
\hline & & \multicolumn{2}{|l|}{ Sagittal } & \multicolumn{2}{|c|}{$\begin{array}{l}\text { Status of teeth } \\
\text { and restorations }\end{array}$} & \multicolumn{2}{|l|}{ Oral health } \\
\hline Lower facial height & Normal & Overjet & $2 \mathrm{~mm}$ & 18 & 38 & Oral Hygiene & Excellent \\
\hline Upper midline to facial & Coincident & Incisor Classification & Class I & 17 & 37 & Phenotype & Thick \\
\hline Lower midline to facial & Coincidetn & Molar relationship ( $r x$ —subdivision) & Class I-Full & 16 & 36 & & \\
\hline Chin point to facial & Coincident & $\begin{array}{l}\text { Molar relationship (sx-subdivi- } \\
\text { sion) }\end{array}$ & Class I_Full & 15 & 35 & & \\
\hline Face: Profile view & & $\begin{array}{l}\text { Canine relationship ( } r x \text { - subdivi- } \\
\text { sion) }\end{array}$ & Class I_Full & 14 & 34 & & \\
\hline Skeletal (severity) & Mild Class III & $\begin{array}{l}\text { Canine relationship (sx-subdivi- } \\
\text { sion) }\end{array}$ & Class I_Full & 13 & 33 & & \\
\hline Smile: analysis & & Vertical & & 12 & 32 & & \\
\hline Smile line & Ideal & Overbite (\%) & Decreased 20\% & 11 & 31 & & \\
\hline Smile arc & Curved & Openbite & - & $21 \mathrm{~F}$ & 41 & & \\
\hline Buccal corridors & Normal & Transverse & & 22 & 42 & & \\
\hline Soft tissue & & Crossbite & Yes-12 & 23 & 43 & & \\
\hline Lip competence & Competent & Displacement & - & 24 & 44 & & \\
\hline Lip catch & Not present & Scissor Bite & - & 25 & 45 & & \\
\hline Naso-labial angle & Normal & Space analysis & & 26 & 46 & & \\
\hline \multirow{16}{*}{\multicolumn{2}{|c|}{$\begin{array}{l}\text { Notes on esthetics: } \\
\text { The main concern of the patient is tooth } 1.2 \text { and } \\
\text { diastema between tooth } 2.3 \text { and } 2.4\end{array}$}} & Crowding upper & Mild (0-4 mm) & 27 & 47 & & \\
\hline & & Crowding lower & $\begin{array}{l}\text { Moderate } \\
(4-8 \mathrm{~mm})\end{array}$ & 28 & 48 & & \\
\hline & & Spacing Upper & - & \multirow{14}{*}{\multicolumn{4}{|c|}{$\begin{array}{l}\text { Treatment goals: } \\
\text { Esthetics: } \\
\text { Function: correction of crossbite tooth } 1.2, \\
\text { correction of crowding lower arch } \\
\text { Dentition: Restoring } 2.1 \\
\text { Biology: no changes needed }\end{array}$}} \\
\hline & & Spacing Lower & - & & & & \\
\hline & & Arch form & & & & & \\
\hline & & Upper & U shape & & & & \\
\hline & & Lower & U shape & & & & \\
\hline & & Occlusal scheme & & & & & \\
\hline & & Lateral excursion right & Canine & & & & \\
\hline & & Lateral excursion left & Canine & & & & \\
\hline & & Protrusive excursion & Incisor & & & & \\
\hline & & Tmd examination & & & & & \\
\hline & & Pain on palpation & No & & & & \\
\hline & & Clicks & No & & & & \\
\hline & & Crepitus & No & & & & \\
\hline & & Mouth opening & Regular & & & & \\
\hline
\end{tabular}

Structure, legend: $\mathrm{O}=$ Restoration, $\mathrm{X}=$ Missing, $\mathrm{A}=$ Abraded, $\mathrm{C}=\mathrm{CARIES}, \mathrm{F}=$ fractured, $\mathrm{R}=$ Root filled, $\mathrm{P}=$ Perio involved

health compared to fixed orthodontic appliances [25]. After treatment, oral hygiene is clearly improved with straight teeth. CAT is extremely complementary in restorative cases: straighten teeth allows and prepares the spaces to perform, when needed, minimally invasive restoration (Fig. 19). Furthermore, in case of implant surgery, it could create the ideal space not only for implant positioning but also for the subsequent restoration. Limitations of aligners in three-dimensional tooth movement are well described in the literature [26], such as extrusion, inclination in vestibular-lingual direction of anterior segment and severe rotation [23, 26-28]. Invisalign Go (Align Technology, San Jose, Calif) is specifically designed for pre-restorative cases, allowing limited movement between second premolar and second premolar in both arches. It is designed especially for restorative dentists to give them the chances to treat a case with inter-disciplinary mindset. To starting using Invisalign Go, every dentist must attend an online or 


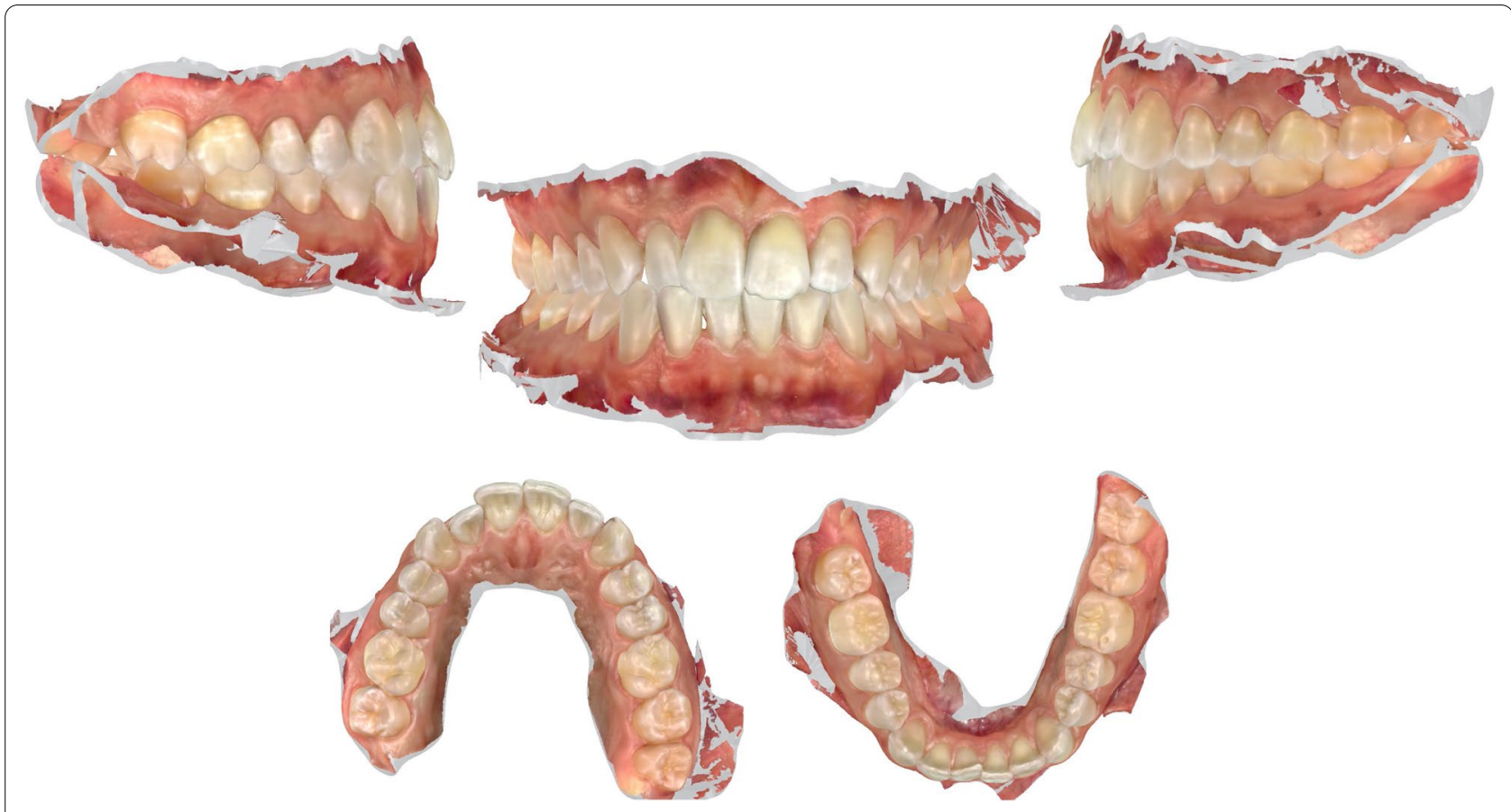

Fig. 3 Case 1, initial situation, digital impression
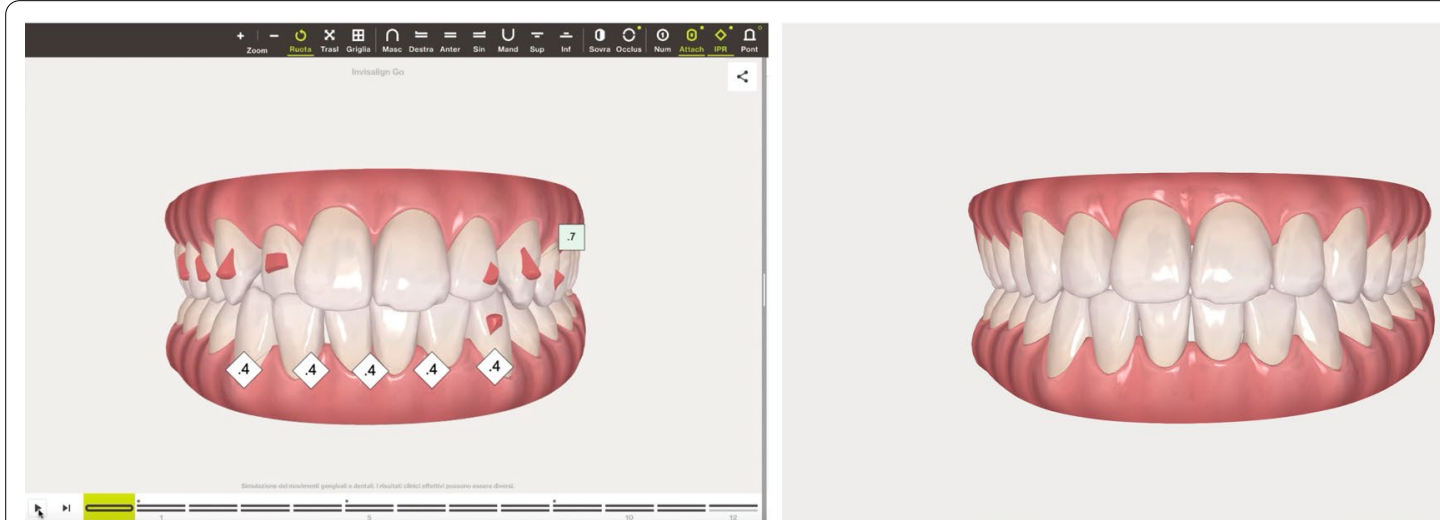

Fig. 4 case 1, initial and final position planned on the Clin Check (Align Technology, San Jose, Calif)

face to face specific training program developed by one of the Authors (R.A.). This program provides a basic level of training for general dentists about clear aligners therapy and offers a continuing mentorship provided by experienced doctors for every step of the treatment, from case selection to retention. Case selection could be one of the major issues for dentist as the system allow to treat a specific range of malocclusion (see Table 3). These criteria could be easily applied to every case by using a specific app (Invisalign Photo Uploader, Align Technology, San Jose, Calif) which immediately evaluate the feasibility of the case with this system through photo analysis. The app guides the clinician to take a specific photo protocol; then, the photos are uploaded and a dedicated software classifies the case as "easy" or "difficult" to treat. If the software evaluates the case as "difficult", this could be referred to a comprehensive 


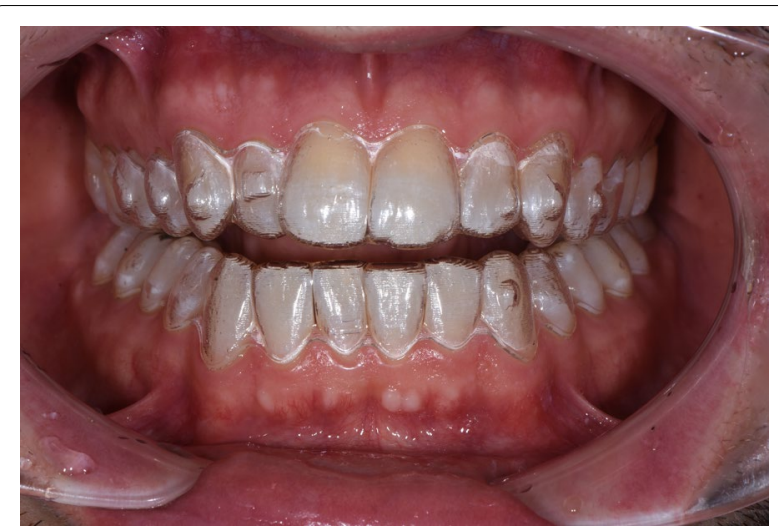

Fig. 5 Case 1, delivery of the first set of clear aligners

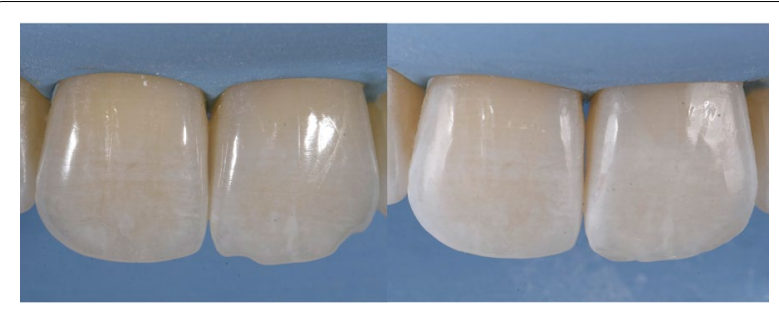

Fig. 6 Case 1, direct restoration on tooth 2.1

Invisalign provider. Generally, following IOTN classification [29], up to grade 3 cases could be treated however patients who have not completed skeletal growth are not suitable for this kind of treatment.
Invisalign Go provides a total of 20 aligners plus two sets of 20 aligners each for refinement. In this paper, the first case required a total of 21 aligners, the second one 24. In the Author's experience cases treated with Invisalign Go usually present this amount of duration. The Clin Check is a powerful tool to plan and to share with the patient the treatment plan. It helps to build a correct therapeutic alliance between clinicians and patients. The possibility to align teeth is extremely useful in a pre-restorative phase, as elicit the chance to work as much as possible at enamel level, which is a favorable prognostic factor for adhesive restorations [30]. In case 1 the correction of cross bite avoided any restorative intervention on tooth 1.2 . In case 2 the Clin Check allowed to measure and create exactly the correct space for tooth 1.2, based on the Bolton analysis (15). An additive restoration was performed to conform the tooth to the contralateral and the correction of the cross bite prevented from occlusal stress and restore function.

The preservation of dental tissue has become possible especially with the spreading and the improvement of modern adhesive partial restorations. The merging of these concepts let clinicians to interrupt the cycle of defective restorations $[31,32]$ that is the cycle of a failed restoration substituted by a larger one, leading to more extensive restorations during years ending in root canal therapy and possibly an implant.

Adhesive dentistry allows to preserve and conserve sound tooth structure: full crown preparation could not

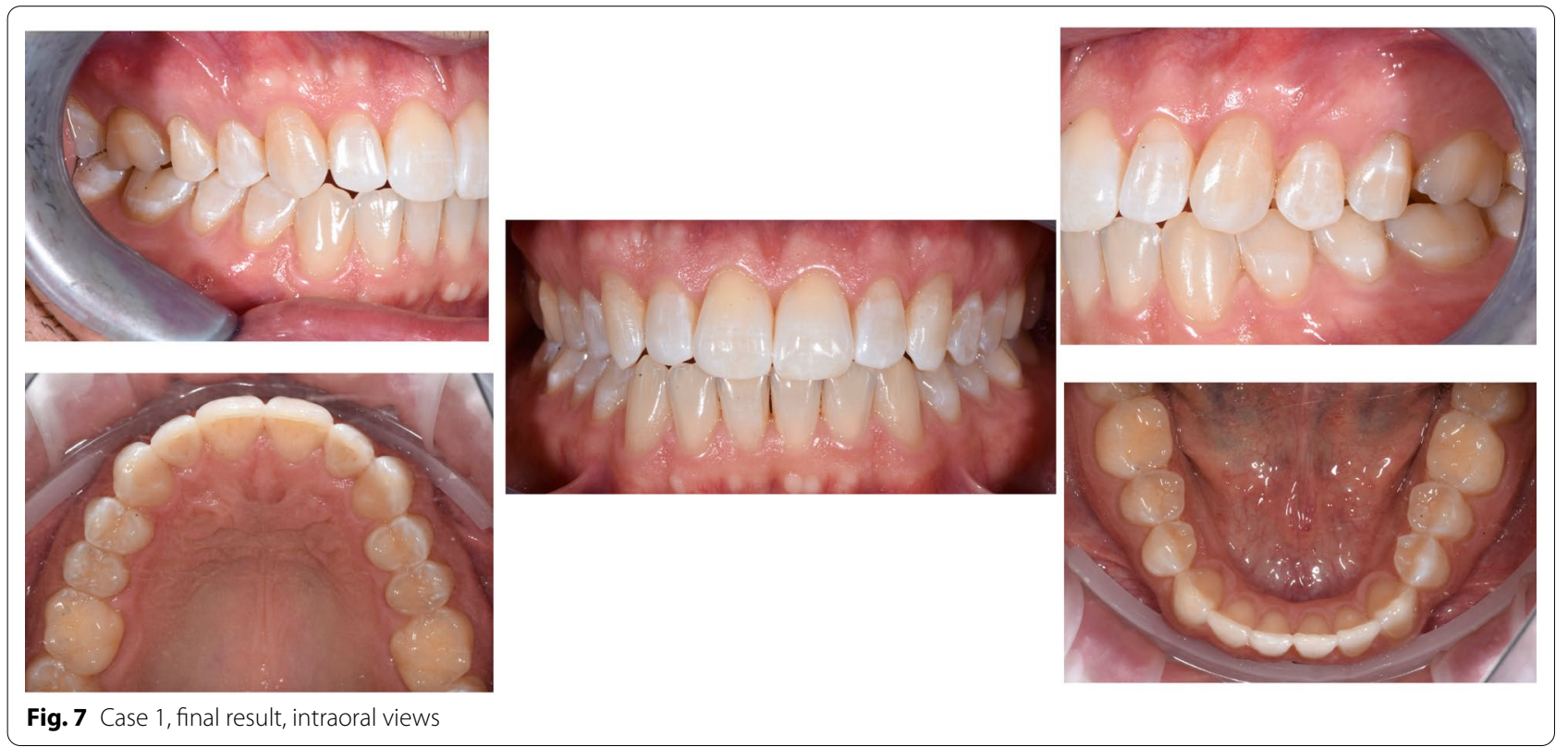




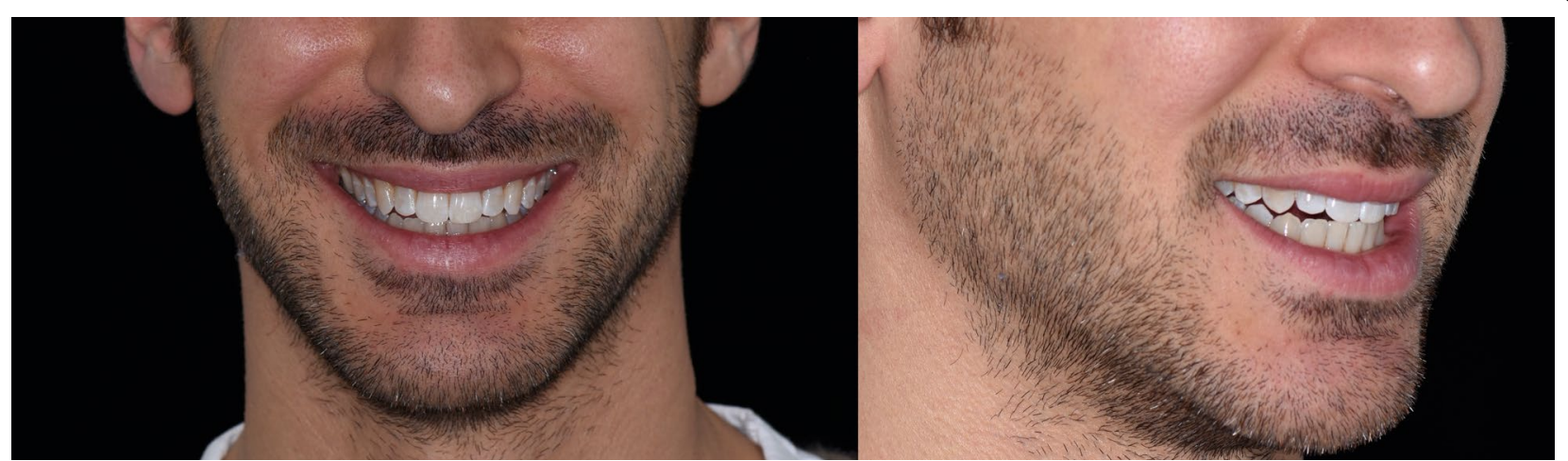

Fig. 8 Case 1, final result, extraoral views

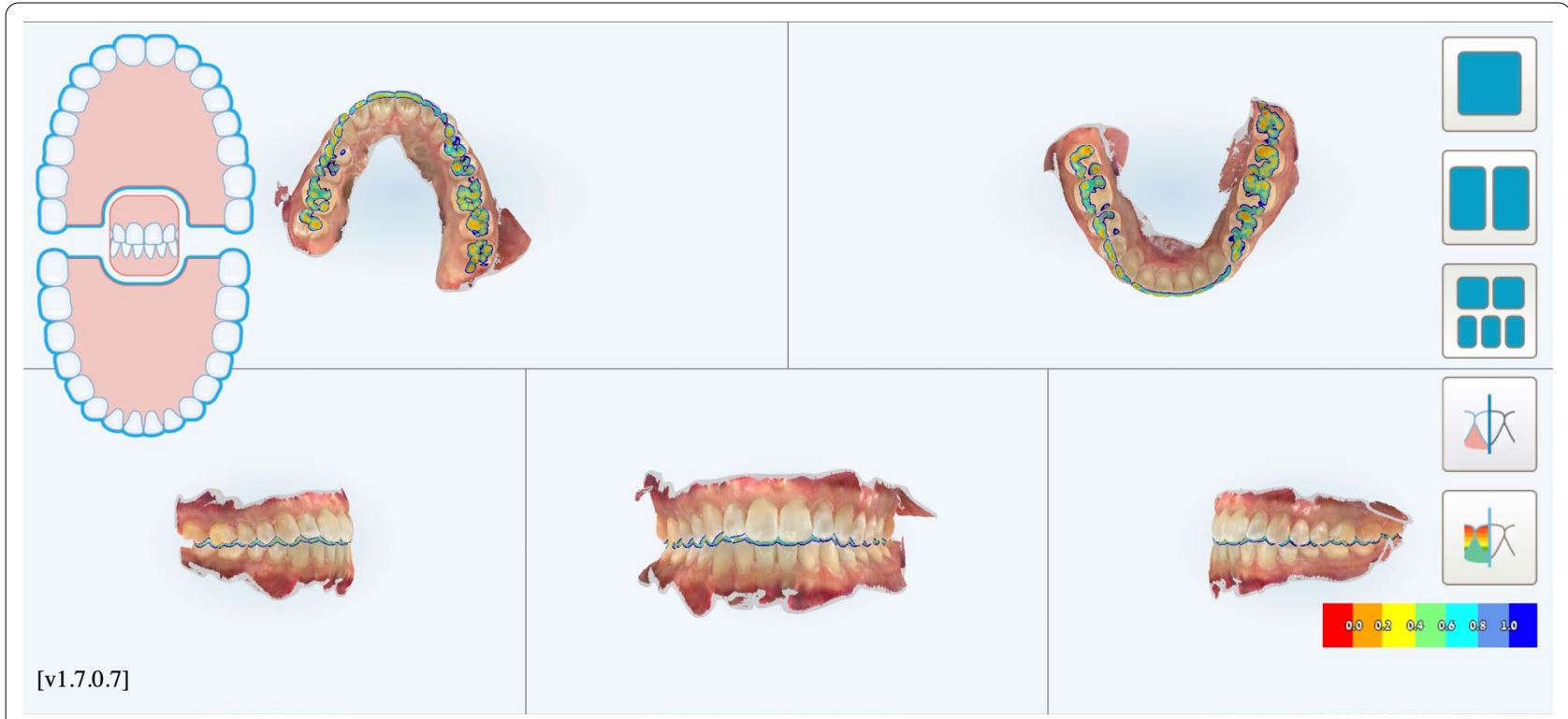

Fig. 9 Case 1, digital impression of the final result

be necessary anymore as long as mechanical retention could be substituted by adhesively bonded restoration to the remaining tooth structure [33], increasing the lifespan of the treated tooth. When it comes to an esthetic area, this approach should be definitely stressed. As dental clinicians, we should be aware that our restorations could not last forever [34]: it is mandatory to inform the patient about pros and cons of every treatment plan.
Oral health is a prerequisite of every dental treatment and esthetic should be evaluated as first parameter during planning. The newly developed five-to-five CAT could be extremely useful for general practitioners in multidisciplinary treatment plan in order to straighten teeth, especially in a pre-restorative phase to allow minimally invasive and adhesive restorations. Future research will be useful to validate this approach, evaluating the predictability of the treatment and its 


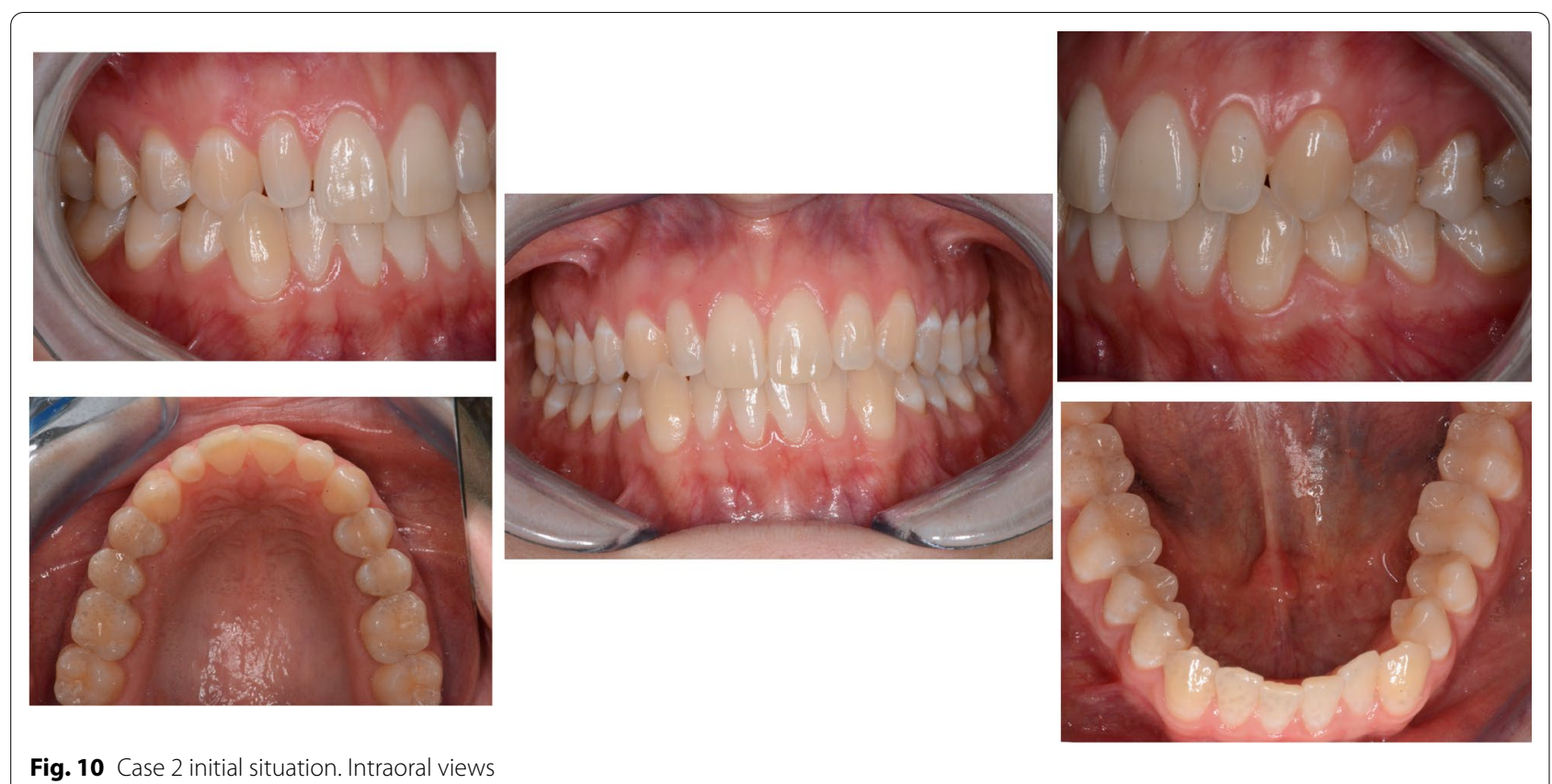

Fig. 10 Case 2 initial situation. Intraoral views
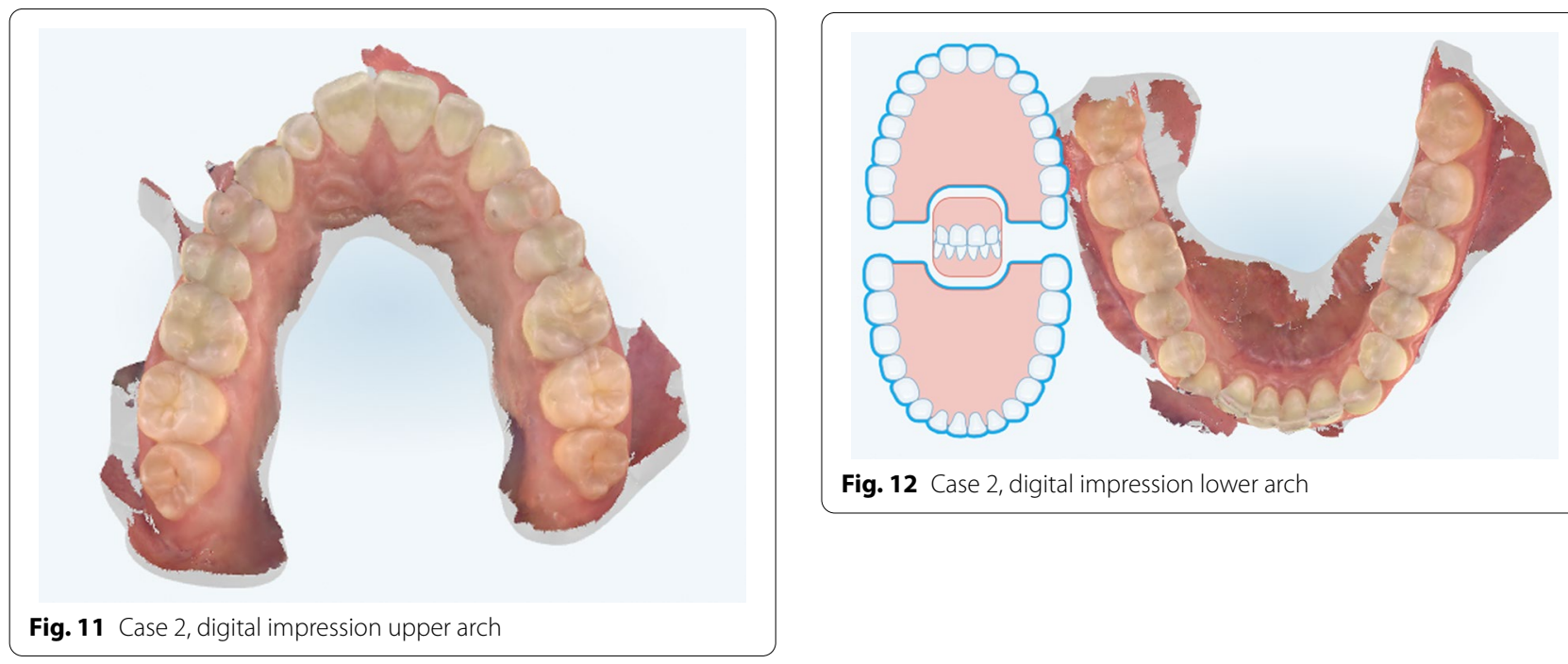

Fig. 12 Case 2, digital impression lower arch 
Table 2 Safe assessment case 2

\begin{tabular}{|c|c|c|c|c|c|c|c|}
\hline \multirow{2}{*}{\multicolumn{2}{|c|}{$\begin{array}{l}\text { Esthetics } \\
\text { Face: frontal view }\end{array}$}} & \multicolumn{2}{|l|}{$\begin{array}{l}\text { Occlusion } \\
\text { (Static and Functional) }\end{array}$} & \multicolumn{2}{|c|}{ Structure } & \multicolumn{2}{|l|}{ Biology } \\
\hline & & \multicolumn{2}{|l|}{ Sagittal } & \multicolumn{2}{|c|}{$\begin{array}{l}\text { Status of teeth } \\
\text { and restorations }\end{array}$} & \multicolumn{2}{|l|}{ Oral health } \\
\hline Lower facial height & Normal & Overjet & $0 \mathrm{~mm}$ & 18 & 38 & Oral Hygiene & Excellent \\
\hline Upper midline to facial & Coincident & Incisor Classification & Class 1 & 17 & 37 & Phenotype & Thick \\
\hline Lower midline to facial & Coincident & Molar relationship (rx-subdivision) & Class I-Full & 16 & 36 & & \\
\hline Chin point to facial & Deviated & Molar relationship (sx- subdivision) & Class I-Full & 15 & 35 & & \\
\hline Face: Profile view & & $\begin{array}{l}\text { Canine relationship (rx-subdivi- } \\
\text { sion) }\end{array}$ & Class I_Full & 14 & 34 & & \\
\hline Skeletal (severity) & Class I & $\begin{array}{l}\text { Canine relationship (sx-subdivi- } \\
\text { sion) }\end{array}$ & Class I-Full & 13 & 33 & & \\
\hline Smile: analysis & & Vertical & & 12 & 32 & & \\
\hline Smile line & Ideal & Overbite (\%) & $15 \%$ & 11 & 31 & & \\
\hline Smile arc & Curved & Openbite & - & 21 & 41 & & \\
\hline Buccal corridors & Normal & Transverse & & 22 & 42 & & \\
\hline Soft tissue & & Crossbite & $1.3 / 4.3$ & 23 & 43 & & \\
\hline Lip competence & Competent & Displacement & - & 24 & 44 & & \\
\hline Lip catch & Not present & Scissor Bite & - & 25 & 45 & & \\
\hline Naso-labial angle & Normal & Space Analysis & & 26 & 46 & & \\
\hline \multirow{16}{*}{\multicolumn{2}{|c|}{$\begin{array}{l}\text { Notes on esthetics: } \\
\text { The main concerns of the patient are teeth } 1.3 \\
\text { and } 4.3 \text { in cross-bite, and tooth } 1.2 \text { that isconoid }\end{array}$}} & Crowding upper & Mild (0-4 mm) & 27 & 47 & & \\
\hline & & Crowding lower & Mild (0-4 mm) & 28 & 48 & & \\
\hline & & Spacing Upper & - & \multirow{14}{*}{\multicolumn{4}{|c|}{$\begin{array}{l}\text { Treatment Goals: } \\
\text { Esthetics: create space for the restoration } \\
\text { of } 1.2 \\
\text { Function: correction of crossbite teeth } \\
\text { 1.3/4.3, correction of lower arch crowding } \\
\text { Dentition: Restoring } 1.2 \\
\text { Biology: no changes needed }\end{array}$}} \\
\hline & & Spacing Lower & - & & & & \\
\hline & & Arch Form & & & & & \\
\hline & & Upper & U shape & & & & \\
\hline & & Lower & U shape & & & & \\
\hline & & Occlusal Scheme & & & & & \\
\hline & & Lateral excursion right & Canine & & & & \\
\hline & & Lateral excursion left & Canine & & & & \\
\hline & & Protrusive excursion & Incisor & & & & \\
\hline & & Tmd Examination & & & & & \\
\hline & & Pain on palpation & No & & & & \\
\hline & & Clicks & No & & & & \\
\hline & & Crepitus & No & & & & \\
\hline & & Mouth opening & Regular & & & & \\
\hline
\end{tabular}



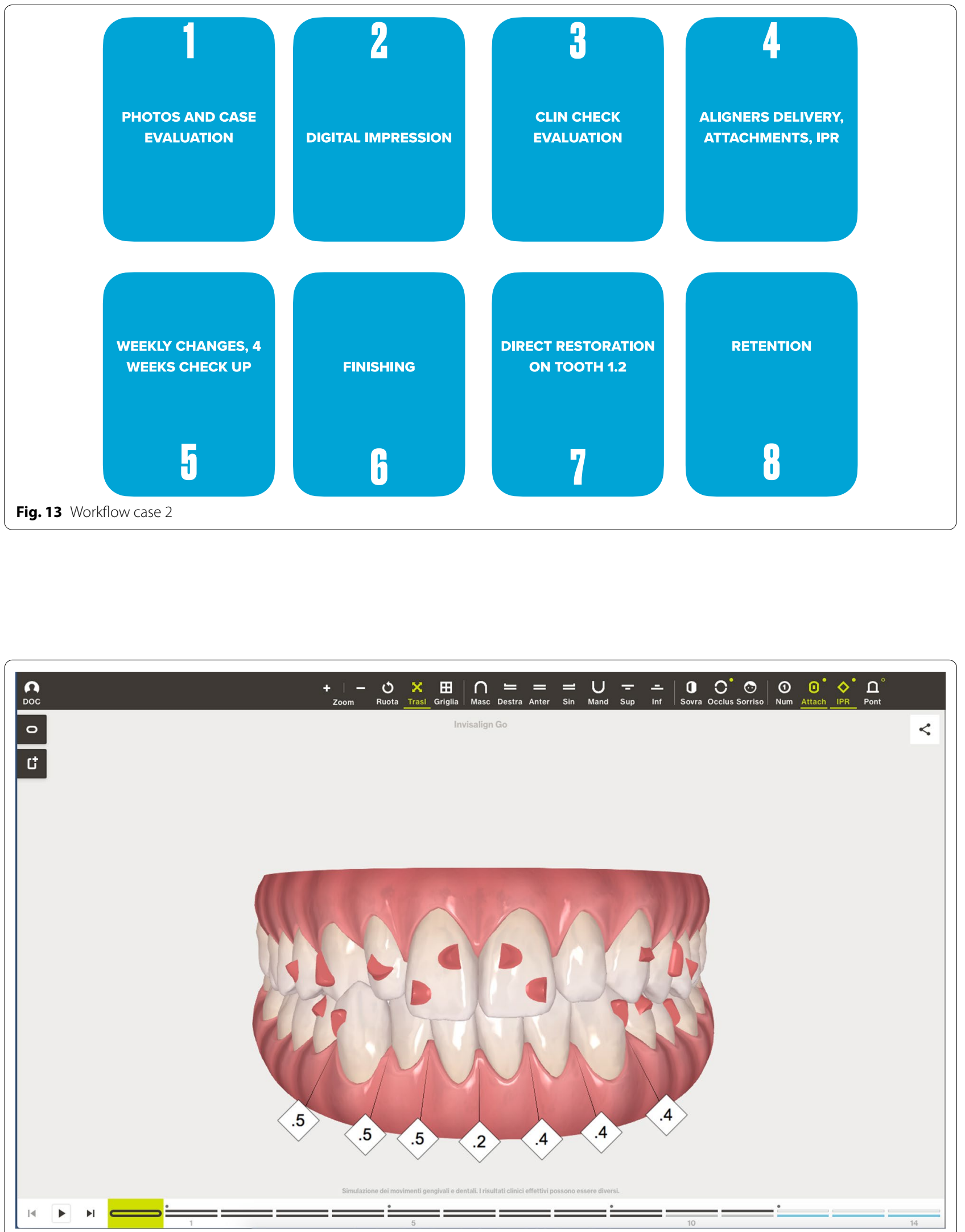

Fig. 14 Case 2, initial position on the Clin Check (Align Technology, San Jose, Calif). The space for the restoration of 1.2 is carefully planned 


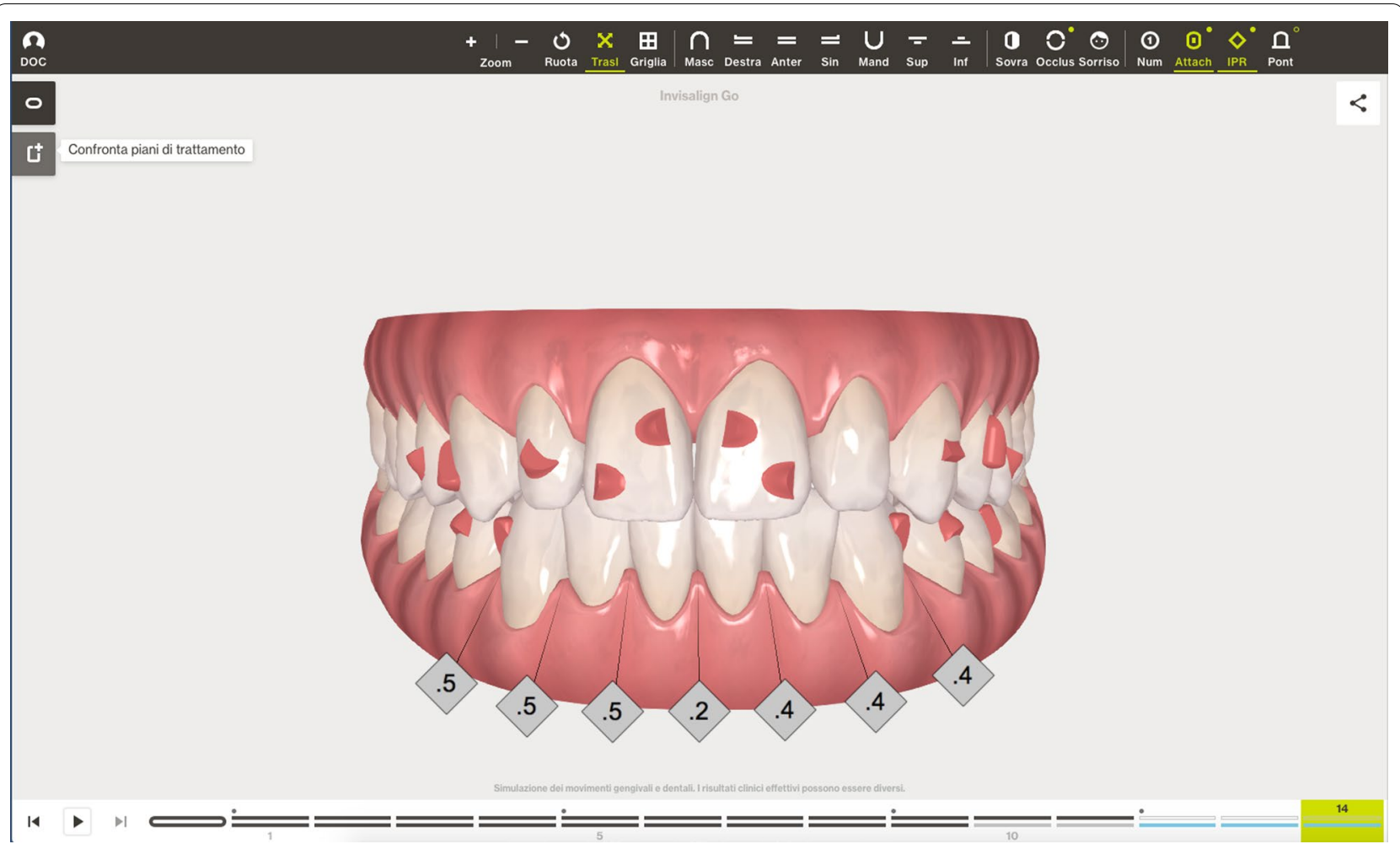

Fig. 15 Case 2, final position on the Clin Check (Align Technology, San Jose, Calif)

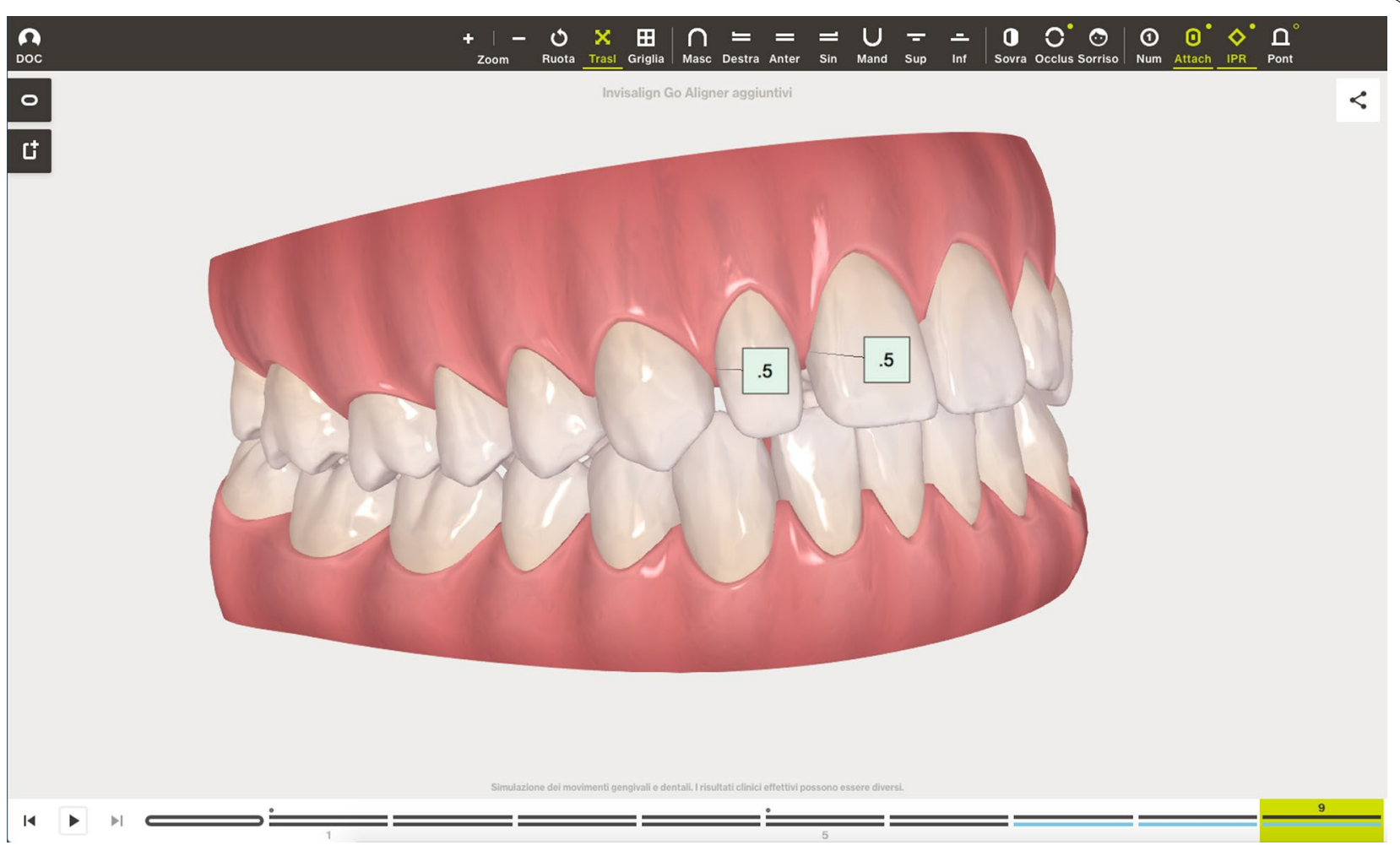

Fig. 16 Case 2, the space for the restoration of 1.2 is carefully planned on the Clin Check (Align Technology, San Jose, Calif) during refinement 


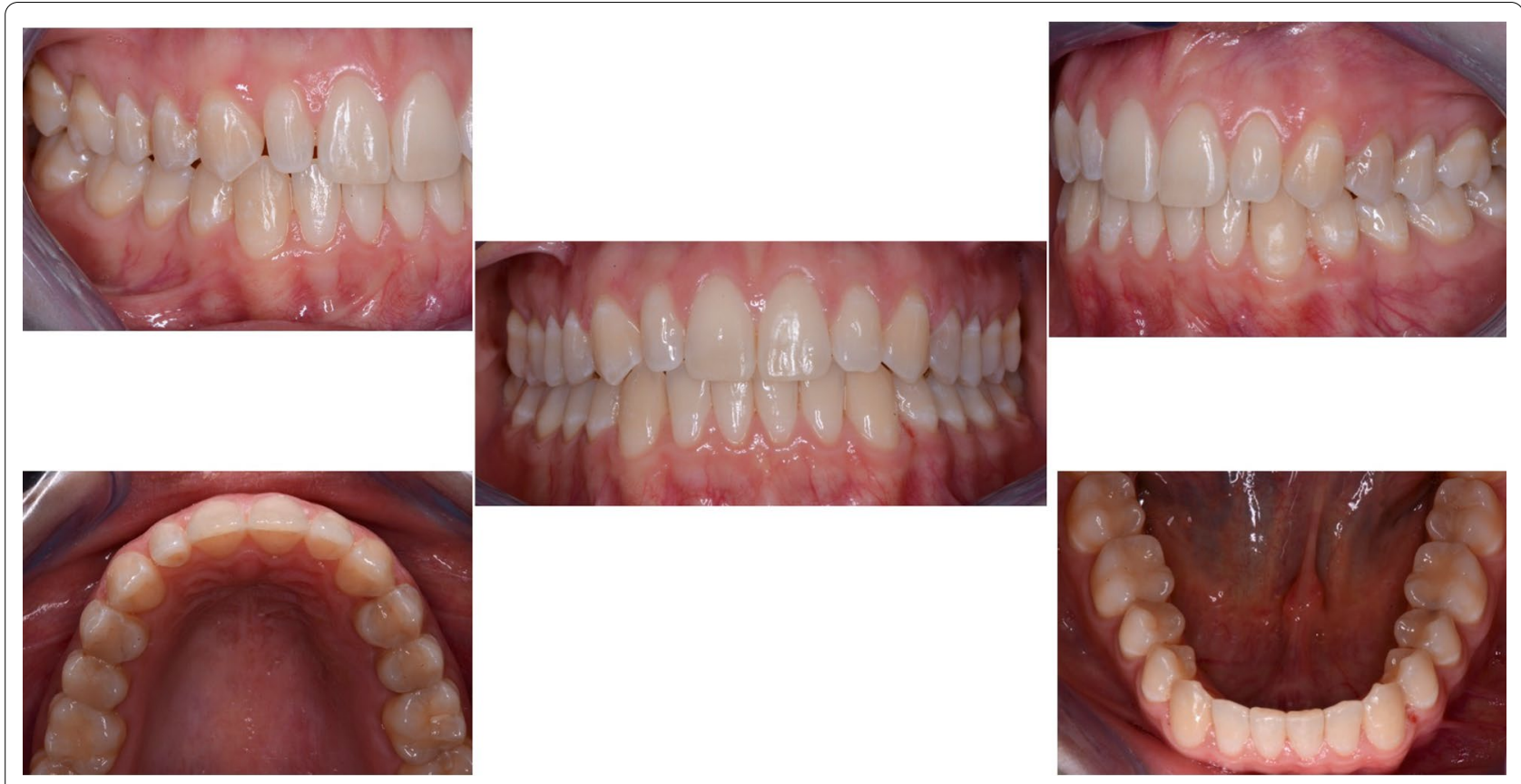

Fig. 17 Final result case 2 after clear aligner therapy
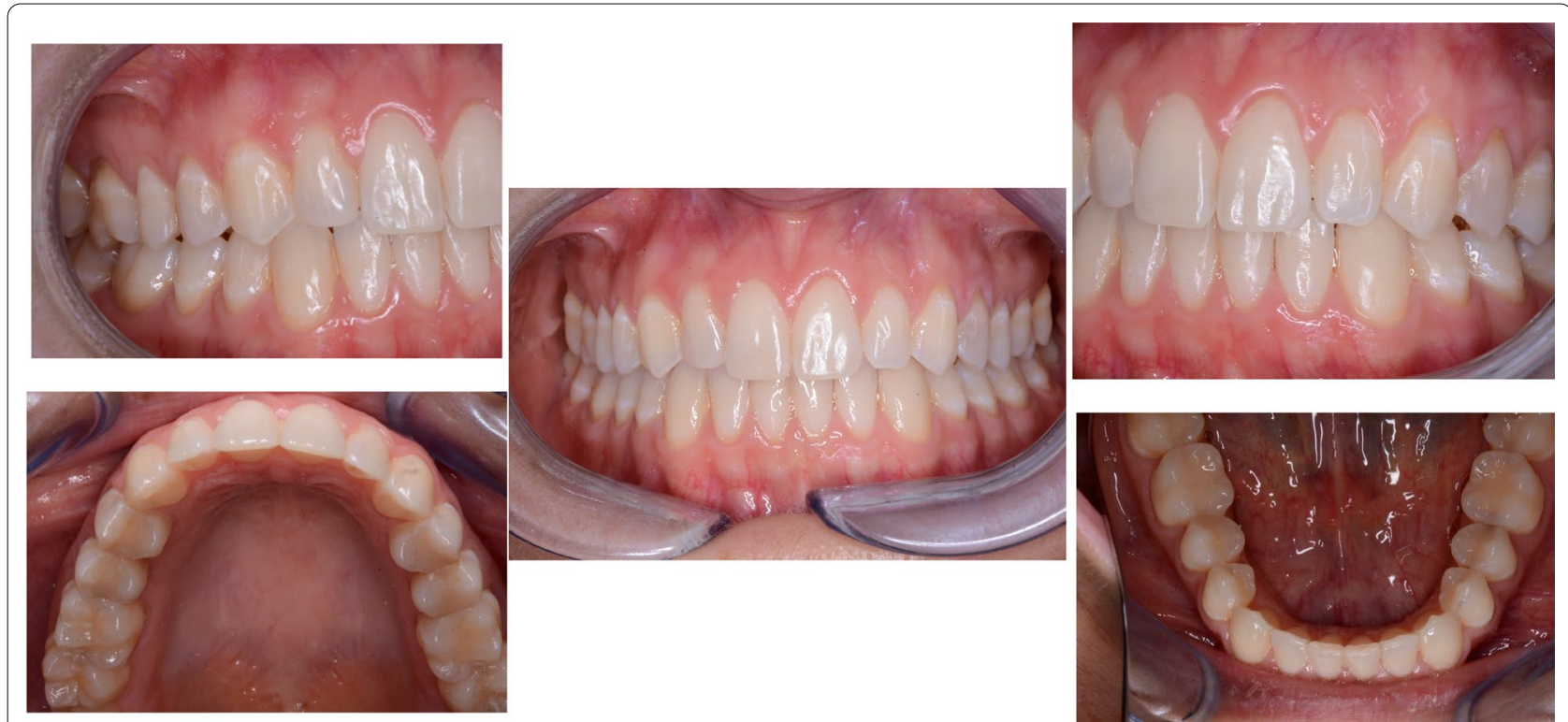

Fig. 18 Final result case 2 after direct restoration on tooth 1.2. Intraoral views

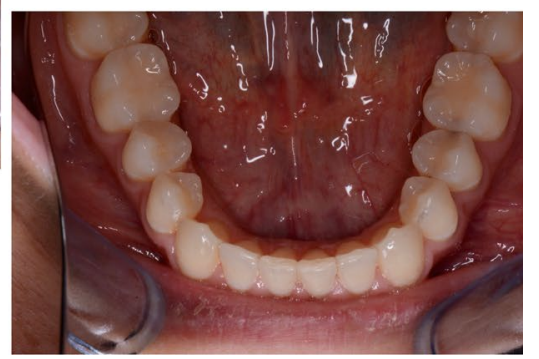



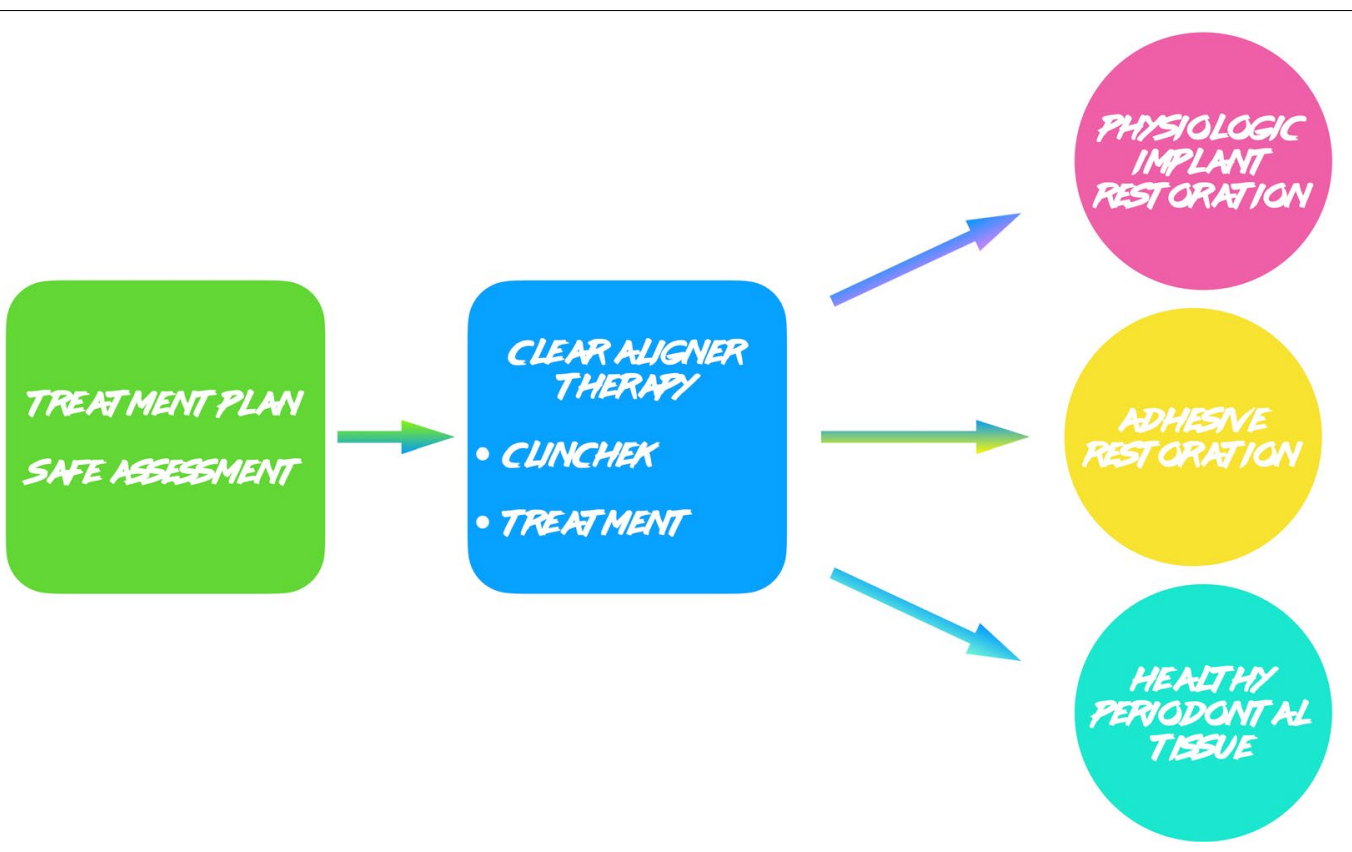

Fig. 19 Ideal restorative workflow with CAT

Table 3 Limits of application of Invisalign Go

\begin{tabular}{ll}
\hline Misalignment & Limit \\
\hline Crowding/spacing & $\leq 7 \mathrm{~mm}$ \\
Arch/width expansion & $4 \mathrm{~mm}$ per arch \\
Overbite (deep vs. open) & $\leq 5 \mathrm{~mm}$ total \\
Midline discrepancy & $1 \mathrm{~mm}$ \\
Treatment includes & Up to 20 \\
- Number of aligners per arch & Two sets $(1,2)$ \\
- Additional aligners &
\end{tabular}

impact on periodontal health and survival and success of restorations.

\section{Abbreviations}

CAT: Clear aligner therapy; SAFE: Stability Assessment Function and Ethics; FGTP: Facially Generated Treatment Planning.

\section{Acknowledgements}

The authors do not have any financial interest in the companies whose materials are included in this article.

\section{Authors' contributions}

Conceptualization T.W., G.M., R.A.; writing —original draft preparation, T.W.; writing - review and editing, G.M.; supervision, R.A. Each author have made substantial contributions to the conception and design the work AND have approved the submitted version (and any substantially modified version that involves the author's contribution to the study); AND have agreed both to be personally accountable for the author's own contributions and to ensure that questions related to the accuracy or integrity of any part of the work, even ones in which the author was not personally involved, are appropriately investigated, resolved, and the resolution documented in the literature. All authors read and approved the final manuscript.

\section{Funding}

This research received no specific grant from any funding agency in the public, commercial, or not-for-profit sectors.

\section{Availability of data and materials}

Not applicable: since the study is a case report, there is not a dataset.

\section{Declarations}

Ethics approval and consent to participate

Not applicable.

\section{Consent for publication}

Written informed consent for personal or clinical details along with any identifying images to be published in this study was obtained from both patients. A copy of the written consent is available for review by the Editor of this journal.

\section{Competing interests}

The authors declare that they have no competing interests.

\section{Author details}

${ }^{1}$ Humanitas Dental Center, Humanitas Research Hospital, Rozzano, MI, Italy. ${ }^{2}$ Private Practice, Rome, Italy. ${ }^{3}$ Clear Aligner Diploma, City of London Dental School, Post Graduate Tutor Kings College, MSC Aesthetic Dentistry, London, UK.

Received: 1 July 2021 Accepted: 23 December 2021

Published online: 29 December 2021

\section{References}

1. Blatz MB, Chiche G, Bahat O, Roblee R, et al. Evolution of aesthetic dentistry. J Dent Res. 2019;98:1294-304.

2. Azarpazhooh A, Dao T, Ungar WJ, Da Costa J, et al. Patients' values related to treatment options for teeth with apical periodontitis. J Endod. 2016:42:365-70. 
3. Touyz LZ, Raviv E, Harel-Raviv M. Cosmetic or esthetic dentistry? Quintessence Int. 1999;30:227-33.

4. Azarpazhooh A, Dao T, Ungar WJ, Chaudry F, et al. Clinical decision making for a tooth with apical periodontitis: the patients' preferred leve of participation. J Endod. 2014:40:784-9.

5. Coachman C, Calamita MA, Sesma N. Dynamic documentation of the smile and the 2D/3D digital smile design process. Int J Periodontics Restorative Dent. 2017;37:183-93.

6. Coachman C, Paravina RD. Digitally enhanced esthetic dentistry - from treatment planning to quality control. J Esthet Restor Dent. 2016; 28(Suppl):1:S3-S4.

7. Ericson D. What is minimally invasive dentistry? Oral Health Prev Dent 2004; 2(Suppl):1:287-92.

8. Ericson D. The concept of minimally invasive dentistry. Dent Update. 2007; 34:9-10, 12-4, 17-8.

9. Simon M, Keilig L, Schwarze J, Jung BA, et al. Forces and moments generated by removable thermoplastic aligners: Incisor torque, premolar derotation, and molar distalization. Am J Orthod Dentofacial Orthop. 2014;145:728-36.

10. Kesling HD. The philosophy of tooth positioning appliance. Am J Orthod. 1945;31:297-304

11. Ponitz RJ. Invisible retainers. Am J Orthod. 1971:59:266-72.

12. McNamara JA, Kramer KL, Juenker JP. Invisible retainers. J Clin Orthod. 1985; 19:570-8.

13. Aulakh RS, Melsen B. When should orthodontics be part of reconstruction of a degenerating dentition? A case report. Prog Orthod. 2011;12:161-8

14. Aulakh $\mathrm{R}$. The anterior ratio: the missing link between orthodontics and aesthetic dentistry. Case Rep Dent. 2013; 2013:470637

15. Spear FM, Kokich VG, Mathews DP. Interdisciplinary management of dental esthetics. J Am Dent Assoc. 2006;137:160-9.

16. Spear FM, Kokich VG. A multidisciplinary approach to esthetic dentistry. Dent Clin North Am. 2007;51:487-505.

17. Bolton WA. Disharmony in tooth size and its relation to the analysis and treatment of malocclusion. Am J Orthod. 1958;28:113-30.

18. Lombardi RE. The principles of visual perception and their clinical application to denture esthetics. J Prosthet Dent. 1973;29:358-82.

19. Kokich VG. Esthetics: the orthodontic-periodontic restorative connection. Semin Orthod. 1996:2:21-30.

20. Spear FM. The maxillary central incisal edge: a key to esthetic and functional treatment planning. Compend Contin Educ Dent. 1999;20:512-6.

21. Kois J. Diagnostically driven interdisciplinary treatment planning. Seattle Study Club J. 2002; 6: 28-34.

22. Keim RG. New possibilities for aligners. J Clin Orthod. 2018;52:195.

23. Rossini G, Parrini S, Castroflorio T, Deregibus A, et al. Efficacy of clear aligners in controlling orthodontic tooth movement: a systematic review. Angle Orthod. 2015;85:881-9.

24. Miller KB, McGorray SP, Womack R, Quintero JC, et al. A comparison of treatment impacts between Invisalign aligner and fixed appliance therapy during the first week of treatment. Am J Orthod Dentofacial Orthop. 2007;131:302.e1-302.e3029.

25. Azaripour A, Weusmann J, Mahmoodi B, Peppas D, et al. Braces versus Invisalign ${ }^{\circledR}$ : gingival parameters and patients' satisfaction during treatment: a cross-sectional study. BMC Oral Health. 2015;23:1-5.

26. Marya A, Venugopal A, Vaid N, Alam MK, Karobari MI. Essential attributes of clear aligner therapy in terms of appliance configuration, hygiene, and pain levels during the pandemic: a brief review. Pain Res Manag. 2020;2020:6677929

27. Tepedino M, Paoloni V, Cozza P, Chimenti C. Movement of anterior teeth using clear aligners: a three-dimensional, retrospective evaluation. Prog Orthod. 2018;19:9

28. Miller RJ, Duong TT, Derakhshan M. Lower incisor extraction treatment with the Invisalign system. J Clin Orthod. 2002;36:95-102.

29. Brook PH, Shaw WC. The development of an index of orthodontic treatment priority. Eur J Orthod. 1989;11:309-20.

30. Gurel G, Sesma N, Calamita MA, Coachman C, et al. Influence of enamel preservation on failure rates of porcelain laminate veneers. Int J Periodontics Restorative Dent. 2013;33:31-9.

31. Elderton RJ. Restorations without conventional cavity preparations. Int Dent J. 1988;38:112-8.
32. Simonsen R. New materials in the horizon. J Am Dent Assoc 1991;122:24-31.

33. Carvalho MA de, Lazari PC, Gresnigt M, Del Bel Cury AA, et al. Current options concerning the endodontically-treated teeth restoration with the adhesive approach. Braz Oral Res. 2018; 32(suppl 1):e74.

34. Pennington MW, Vernazza CR, Shackley P, Armstrong NT, et al. Evaluation of the cost-effectiveness of root canal treatment using conventional approaches versus replacement with an implant. Int Endod J. 2009:42:874-83.

\section{Publisher's Note}

Springer Nature remains neutral with regard to jurisdictional claims in published maps and institutional affiliations.
Ready to submit your research? Choose BMC and benefit from

- fast, convenient online submission

- thorough peer review by experienced researchers in your field

- rapid publication on acceptance

- support for research data, including large and complex data types

- gold Open Access which fosters wider collaboration and increased citations

- maximum visibility for your research: over 100M website views per year

At BMC, research is always in progress.

Learn more biomedcentral.com/submissions 